\title{
Mastoid Osteoma Rare Event: A Case Report
}

\author{
Tawfiq Khurayzi ${ }^{1 *}$ and Yahia Alahmari ${ }^{2}$ \\ ${ }^{1}$ Otolaryngology department, King Fahad Central Hospital, Jizan, KSA \\ ${ }^{2}$ Otolaryngology department, consultant otology neurotology, Khamis Mushait General Hospital, KSA
}

Submission: July 22, 2018; Published: July 25, 2018

*Corresponding author: Tawfiq Khurayzi, Otolaryngology department, King Fahad Central Hospital, Jizan, KSA. Email: tawfiqaakk@hotmail.com

Abstract

We present adult man with rare benign temporal bone neoplasm which is mastoid osteoma. All of clinical presentation, radiological findings and histopathological examination reveal mastoid osteoma. This study presents a rare localization of such benign tumor in the head and neck.

Keywords: Mastoid Osteoma; Head and Neck Osteoma; Mastoid Neoplasm; Temporal Bone Neoplasm

\section{Introduction}

Mastoid osteoma is a rare tumor with incidence of $0.1-1 \%$ of all benign head and neck tumors. Mastoid osteoma is still considered as rare event and few cases having been reported in the literature [1,2]. Osteomas are benign mature bony growths. In addition, it is osteoblastic activity mesenchyme tumours which are more common in paranasal sinuses [3,4]. These lesions are benign, slow growing, and commonly asymptomatic [5]. Computer tomography (CT) is the gold standard for diagnosis $[6,7]$. The imaging appearance usually reflects the underlying pathology and need to be support by histopathological finding. Osteoma can lead to complications or mass effect on functional and cosmetic of adjacent structures, then the surgical excision is the treatment of choice $[8,9]$.

\section{Case Report}

A 45-year- old man, presented to otology clinic with left painless post auricular swelling for 10 years. He also complained of mild chronic decrease hearing in both side. However, he does not have any other significant symptoms notably no ear discharge. Past surgical and medical history were unremarkable. On physical Examination, there was a single mass at the left posterior auricular. Measured $5 \times 5 \mathrm{~cm}$ over mastoid bone with hard, not fluctuant, not tender mass and not pulsatile without skin change. Originating from the lateral surface of the left mastoid posterior to tangent of the posterior border of external auditory canal. Left ear pinna, external auditory canal and tympanic membrane was normal. Other side, the right mastoid area and otological examination normal. No head and neck lymphadenopathy and the rest of E.N.T. examination was within normal. Audiological assessment done, including pure tone audiometry (PTA), speech audiometry and impedance. It showed bilateral symmetrical mild conductive hearing loss and more severity at high frequency. Speech reception threshold was $20 \mathrm{~dB}$ for both sides (Figure 1). Moreover, speech discrimination score for right ear was $94 \%$ and $92 \%$ for left side. Tympanogram was type A in both side. Normally present acoustic reflex.

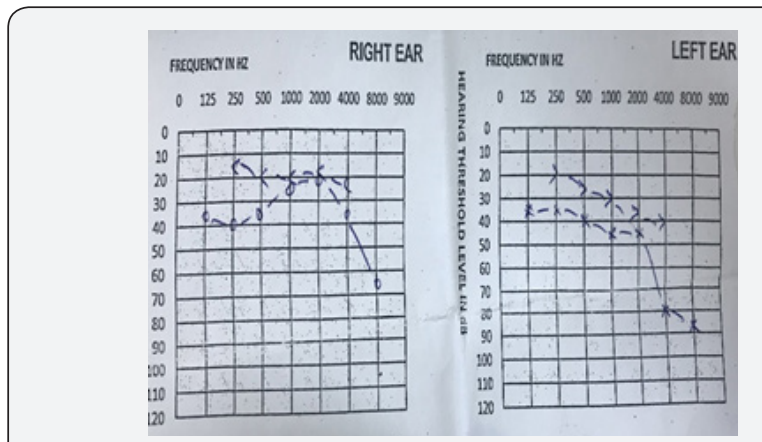

Figure 1: Pure tone audiomatery showing bilateral mild condactive hering loss.

We are requested temporal bone high-resolution computer tomography (HRCT) scan, HRCT showed well-defined bony mass from left mastoid bone posteriorly measuring $3 \times 2.3 \times 3.2 \mathrm{~cm}$. growing superficially without bony destruction in bone or changing in mastoid air cells. Both side middle ear cavities were normal and both external auditory canals were normal (Figure 2). After history and clinical examination radiological investigation finding we are made our diagnosis as left benign mastoid osteoma. This was confirmed by a histopathological report. After discussion with the patient, we decided to excise the lesion under general anesthesia. Surgery was performed with no difficulties or bleeding, a bony mass completely dissected and Left ear pinna, external auditory canal and tympanic membrane was normal intraoperative (Figure 3). Then the specimen sent for 
histopathological study. Histopathological study revealed benign bone forming tumor composed of compact mature trabecular bone within paucicellular fibrous stroma, no evidence of malignancy and histopathological diagnosis is mastoid osteoma (Figure 4). Postoperatively the patient showed complete healing of skin over excise area without residual mass. Our patient now been followed for one year and he showed no new regrowth or active symptoms.

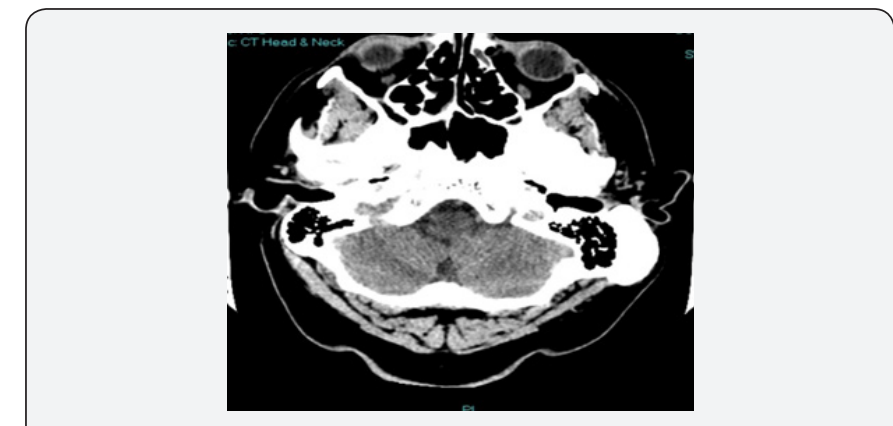

Figure 2: High-resolution computer tomography showing well-defined bony mass over left mastoid bone.

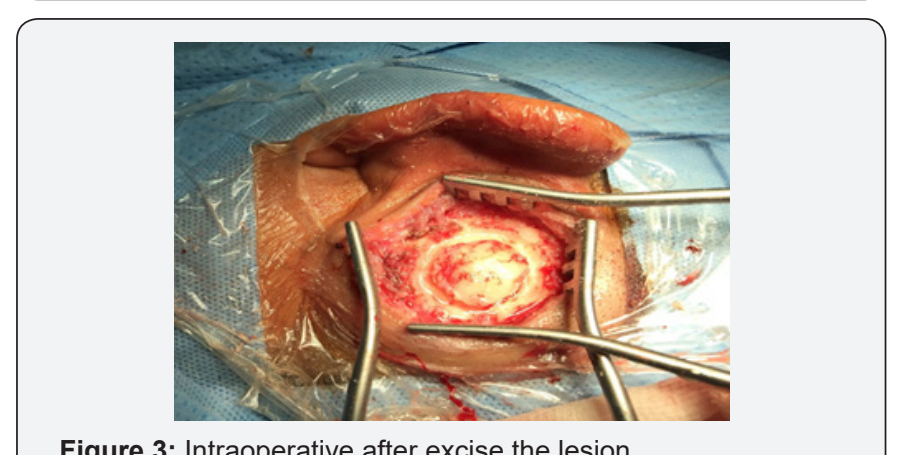

Figure 3: Intraoperative after excise the lesion.

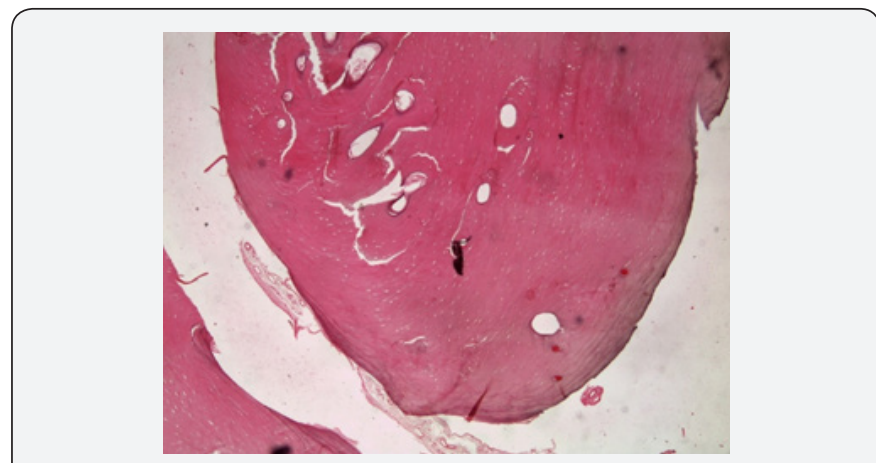

Figure 4: H\&E stain, Outer surface is sharply demarcated of composed dense and compact bone.

\section{Discussion}

Osteomas are benign mature bony growths. In addition, it is osteoblastic activity mesenchyme tumours which are more common in paranasal sinuses commonly found in the frontal and ethmoidal sinuses and less common in the mandible and rare in the temporal bone $[3,4]$. Osteomas are commonly reported in the external auditory canal, bone of middle ear, styloid process, temporomandibular joint, petrous bone, but very rare in the mastoid bone [6]. Mastoid osteoma is rare tumors and still incidence less than $1 \%$ of all benign head and neck tumours. So, few reported cases as Mastoid osteoma in the literature [1,2]. Till now no clear etiological factor identified. Its occurrence may be divided into syndromic such as Gardener's syndrome and nonsyndromic with contributing factors such as inflammatory condition, chronic infection, stress pressure area, trauma, metaplasia, surgery, irradiation, pituitary dysfunction and genetics $[1,3,7,10]$. Mastoid osteomas are usually asymptomatic over many years and painless like in our case. Generally, their growth progresses extra cranially which can be seen as a smooth swelling, bony hard in consistency. Large swellings are unsightly and may cause difficulty to spectacle wearers [10]. Overlying skin usually appears to be normal. In the neck region, pain maybe caused by irritation of great auricular or small occipital nerves.

There is difficulty to classify type of Mastoid osteomas on clinical presentation, duo to usually all type have similar presentations. On the other hand, it can classify on histopathological presentation. Osteoma of mastoid reported in literature as: osteoma compactum, cartilagineum osteoma and osteoma cancellare based on histology [4,6]. Compact osteomas have a wider base and slow growing usually but in cartilagineum osteomas are more likely to be pedunculated form and grow relatively faster [5]. CT scan is the imaging considered as the modality of choice for osteomas [6,7]. On imaging, osteoma be a rounded bone lesion on the mastoid outer cortex, distinctive margins with sessile or pedunculated base. Osteomas may extend into the petrous bone of the temporal bone or adjacent to the horizontal semicircular canal, ossicles and facial nerve but it is a rare [6]. Differential diagnosis of temporal osteoma includes osteoblastic metastasis, osteosarcoma, ossifying fibroma, isolated eosinophilic granuloma, Paget's disease, giant cell tumour, osteoid osteoma, calcified meningioma, hemangioma, and monostotic fibrous dysplasia [5,4,9]. Treatment of choice it is surgical resection and most common indication being cosmetic disfigurement, associated symptoms and to prevent its later complications [3]. Osteoma lesions if indicated to excise, it need to excise complete and drilled until normal bone is exposed [1]. Safe margin should be removed and if it is close to important structures such as the facial nerve canal or bony labyrinth, a subtotal excision is adopted to preserve function [11]. Rare recurrence in osteoma if excised completely (9). Transformation to Malignant is yet to be reported [7].

\section{Conclusion}

Mastoid osteomas of temporal bone are rare benign slow growing tumors of the head and neck. Most patients asymptomatic unless it gradually increases in size to cause cosmetic disfigurement and pain. Non-contrast CT as modality of choice and it will help to show the extension of lesion. Complete surgical excision is treatment of choice till normal healthy bone exposed for prevent recurrences and achieves good cosmetic results. 


\section{References}

1. Rahul Hajare (2018) Detection of High Addictive Habits Circulating Office in Charge of Private Pharmacy Institutions in Pune University India (Evidence Based Study of Late Report Office in Charge to College). Clinical Biotechnology and Microbiology 2(3): 377-381.

2. Rahul Hajare (2017) The Aggression is an Early Cause of Cancer. A Narrative Review of Classical to Modern Scientific Literature. Chronicle of Medicine and Surgery 1(2): 67-68.

3. Hajare R (2017) Can Otolaryngology Capture Window Cancer in Middle Adulthood? Ann Clin Lab Res 5(4): 205.

4. Rahul H (2018) Shocking Link of Rapid Rise in Pre-Cancer among the Healthy Adults in Pharmaceutical Institution Pune University India Living With Low Oxygen and Poor Sanitation Environment: Affordable Treatment Rate Three-Times Over. Glob J Add \& Rehab Med 5(5): 555673.

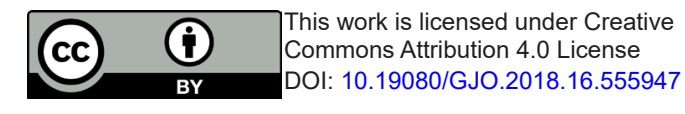

5. Rahul Hajare (2018) There is no Cure for the Cancer of Stupidity. Organic \& Medicinal Chem IJ 5(1): 555655.

6. Rahul Hajare (2018) An Attempt to Eradicate Alcohol Dependency from Adult Men in Service Privately Managed Pharmaceutical Institutions in India. Toxicology and Applied Pharmacology Insights 1(1): 180001.

7. Rahul H (2018) Shocking Link of Rapid Rise in Pre-Cancer among the Healthy Adults in Pharmaceutical Institution Pune University India Living with Low Oxygen and Poor Sanitation Environment: Affordable Treatment Rate Three-Times Over. Glob J Add \& Rehab Med 5(5): 555673.

8. Rahul A Hajare (2018) 909090 Formulas and Symptoms of Adrenal Fatigue Syndrome (AFS) of Adult Men. Orthop \& Spo Med Op Acc J 1(3).

\section{Your next submission with Juniper Publishers will reach you the below assets}

- Quality Editorial service

- Swift Peer Review

- Reprints availability

- E-prints Service

- Manuscript Podcast for convenient understanding

- Global attainment for your research

- Manuscript accessibility in different formats ( Pdf, E-pub, Full Text, Audio)

- Unceasing customer service

Track the below URL for one-step submission https://juniperpublishers.com/online-submission.php 